\title{
Lexicografia Pedagógica: história e panorama em contexto brasileiro
}

\author{
Pedagogical Lexicography: history and Brazilian context scene
}

Mariana Daré Vargas*

\begin{abstract}
RESUMO: O objetivo deste artigo é apresentar reflexões sobre questões teóricas relacionadas à Lexicografia Pedagógica, de modo a estabelecer um panorama dessa disciplina em contexto brasileiro. Resgatam-se as origens da Lexicografia Pedagógica, no final do século XIX e começo do século XX, quando da mudança do paradigma de ensino de línguas (MOLINA GARCÍA, 2006). Apresentam-se conceitos de Lexicografia Pedagógica atribuídos por especialistas (DUBOIS; DUBOIS, 1970; RUNDELL, 1998; HARTMANN, 2001; MOLINA GARCÍA, 2006; DURAN; XATARA, 2007; DURAN, 2008; HERNÁNDEZ, 2008; WELKER, 2008; KRIEGER, 2011; WELKER, 2011; DE SCHRYVER, 2012). Por fim, discutem-se as áreas com as quais essa ciência faz interface e propõe-se o panorama da Lexicografia Pedagógica em contexto brasileiro, proposta ampliada de Duran e Xatara (2007), da qual fazem parte, além de aluno(a), professor(a), lexicógrafo(a) e editor(a), o Governo Federal.
\end{abstract}

PALAVRAS-CHAVE: Lexicografia Pedagógica. História da Lexicografia Pedagógica. Metalexicografia Pedagógica. Ensino-aprendizagem de línguas.

\begin{abstract}
The purpose of this article is to present reflections on theoretical issues related to Pedagogical Lexicography, in order to establish a panorama of this discipline in a Brazilian context. The origins of this discipline are rescued in the late nineteenth and early twentieth century when the paradigm of language teaching changed (MOLINA GARCÍA, 2006). Pedagogical Lexicography concepts are presented by specialists (DUBOIS; DUBOIS, 1970; RUNDELL, 1998; HARTMANN, 2001; MOLINA GARCÍA, 2006; DURAN; XATARA, 2007; DURAN, 2008; HERNÁNDEZ, 2008; WELKER, 2008; KRIEGER, 2011; WELKER, 2011; DE SCHRYVER, 2012). Finally, we discuss the areas with which this science interfaces and propose the panorama of the Pedagogical Lexicography in a Brazilian context, an extended proposal of Duran and Xatara (2007), which includes, besides students, teacher, lexicographer and publisher, the Brazilian Government.
\end{abstract}

KEYWORDS:

Pedagogical

Lexicography. History of Pedagogical Lexicography. Pedagogical Metalexicography. Languages teaching and learning.

\footnotetext{
* Doutora em Linguística e Língua Portuguesa. Realiza estágio de Pós-doutorado em Linguística e Língua Portuguesa, na Universidade Estadual Paulista "Júlio de Mesquita Filho" (UNESP), com bolsa de Pós-doutorado Júnior do CNPq (Conselho Nacional de Desenvolvimento Científico e Tecnológico).
} 


\section{Introdução}

Neste artigo, lançamos um olhar sobre questões teóricas relacionadas à Lexicografia Pedagógica. Inicialmente, resgatamos suas origens e investigamos os conceitos apresentados por especialistas, brasileiros e estrangeiros, para essa disciplina, a fim de estabelecer uma definição precisa desta. Por fim, apresentamos, com base na proposta de Duran e Xatara (2007), um panorama dos elementos da Lexicografia Pedagógica em contexto brasileiro, bem como as áreas com as quais dialoga.

\section{Origens da Lexicografia Pedagógica}

No final do século XIX e início do século XX, mudou-se o paradigma do ensino de línguas, uma verdadeira revolução, segundo Molina García (2006): os estudos realizados por pedagogos e linguistas vão em direção de um método de ensino mais natural e direto. No final do século XIX e início do século XX, o Método Direto influenciou sobremaneira o ensino de línguas estrangeiras (doravante LE). Essa abordagem propunha que se aprendia uma língua falando, logo, não se recorria à tradução, dava-se primazia à oralidade, ocupando a pronúncia lugar de destaque, e a aprendizagem da gramática era dedutiva, pois as regras de funcionamento da língua eram inferidas por meio da observação do idioma em uso.

Essa mudança na área do ensino-aprendizagem de línguas refletiu no campo da Lexicografia, emergindo a necessidade de mudar a apresentação do léxico e da gramática nos dicionários voltados ao ensino, de modo a satisfazer as necessidades de aprendizagem dos usuários.

A Lexicografia Pedagógica, de acordo com Molina García (2006), nasceu dessa revolução, desse "giro de 180 graus", da percepção, por parte de um grupo de professores, de que o dicionário do aprendiz de línguas deve ser diferente daquele de um falante da língua materna (doravante LM), sendo necessária, portanto, a 
adequação às necessidades do consulente-aprendente de LE, inclusive porque este não era, e ainda não é, "letrado" em seu uso, devido às esporádicas vezes em que recorria à obra lexicográfica.

Interessante observar que, desde o princípio, de modo incipiente, já se pensava no letramento lexicográfico do estudante-usuário do dicionário e do professor, temática que, desde então, vem sendo debatida e ampliada. De nosso ponto de vista, o conceito de letramento lexicográfico está relacionado às práticas pedagógicas que visam propiciar adequada formação lexicográfica dos alunos, tanto os que não vão se tornar professores(as) de línguas, como aqueles que, um dia, serão professores(as). Essa formação lexicográfica, tal como o letramento, propicia aos estudantes apropriarem-se da obra lexicográfica, de modo a perceberem-na não apenas como um livro de consultas esporádicas sobre as definições ou equivalentes das palavras, mas como um objeto intermediador das práticas sociais de linguagem. Nessa perspectiva, o dicionário é concebido como suporte para a construção dos conhecimentos linguísticos, a produção e a compreensão dos mais diferentes tipos e gêneros textuais.

Podemos concluir, portanto, que ser letrado lexicograficamente é conhecer todas as possibilidades e potencialidades da obra lexicográfica, reconhecer seu valor social e a ideologia que a perpassa, por meio de um trabalho sistemático sobre o seu funcionamento e a(s) língua(s) que apresenta.

A publicação do capítulo de livro "O dicionário: estudo do vocabulário", do linguista inglês Henry Sweet, em 1899, é tida como marco inicial de pesquisas na área da Lexicografia Pedagógica, embora Johnson, em 1747, já houvesse pensado sobre o papel do dicionário no ensino de línguas: “O valor do trabalho lexicográfico deve ser estimado no uso: que o dicionário satisfaça apenas aos críticos não é suficiente, a 
menos que, ao mesmo tempo, ensine seu usuário" (apud HARTMANN, 1983, p. 9, tradução nossa) ${ }^{1}$.

Desde então, conforme Hartmann (1983), pesquisas na área do léxico avançaram consideravelmente e elaboraram-se repertórios lexicais, tais como, listas de vocabulário e minidicionários, em uma tentativa de simplificação do léxico para o aprendente, considerados o germe dos primeiros dicionários pedagógicos. Posteriormente, produziram-se os primeiros dicionários monolíngues de língua inglesa para estudantes.

Segundo Molina García (2006) e Welker (2008a, 2011), a partir do marco inicial e ao longo do século XX, Thorndike (1928), Odgen, Harold Palmer, Michael West e A. S. Hornby (década de 1930), L. V. Ščerba (1940), Zgusta (1971), Dubois e Dubois (1971), Hausmann (1974, 1977, 1989), Wiegand (1977), Kromann, Riber e Rosbach (1984) abordaram questões relacionadas ao dicionário no ensino-aprendizagem de língua(s), especialmente no âmbito da língua inglesa.

Em razão das limitações de espaço e, sobretudo, porque, no Brasil, esta é uma área relativamente recente, apresentamos um estado da arte dessa ciência nas últimas duas décadas, de Hartmann (1992) a De Schryver (2012), em cenário nacional e internacional.

\section{A Lexicografia Pedagógica sob a visão de pesquisadores nacionais e estrangeiros}

Rundell (1998) trata das tendências na Lexicografia Pedagógica inglesa, fazendo um resgate de fatos e nomes importantes no século XX para essa área. Hornby, West e Palmer são mencionados, pois se preocuparam com as necessidades de aprendentes de inglês como LE, especialmente Hornby, o qual deixou um legado com a obra Idiomatic and Syntactic English Dictionary (1942), que ditou parâmetros lexicográficos aos

\footnotetext{
${ }^{1}$ The value of a work must be estimated by its use: It's not enough that a dictionary delights the critic, unless at the same time it instructs the learner.
} 
dicionários monolíngues para aprendentes produzidos depois da década de 1940. De acordo com o lexicógrafo, vocabulário controlado para definições, orientação pedagógica dos exemplos, presença de unidades fraseológicas e uso de corpus foram questões pensadas ao longo do século XX e, aos poucos, incluídas nas obras lexicográficas para estudantes não nativos de língua inglesa. O corpus, para Rundell, é, nos anos finais da década de 1990, a grande revolução na Lexicografia Pedagógica, porque proporciona um retrato fiel da língua em uso, desvelando suas regularidades, com fraseologias, colocações e preferências contextuais. A ascensão do corpus lexicográfico leva a, mais uma vez, ser repensado o papel da prática lexicográfica e os estudos sobre ela, no âmbito da educação, enfatizando a necessidade de a Lexicografia Pedagógica ser utilitária, isto é, proveitosa aos usuários do dicionário, produzindo obras lexicográficas que atendem às suas necessidades e habilidades linguísticas.

Sobre a revolução trazida pelo corpus ao campo da Lexicografia Pedagógica, Hartmann, em 1992 (p. 153 apud RUNDELL, 1998, p. 338), afirma: “Sinto que estamos apenas no começo de um empolgante período de solução de problemas reais" (tradução nossa) ${ }^{2}$. Afirmação que Rundell, seis anos mais tarde, complementa:

O paradoxo aqui (e isso é o que faz da Lexicografia Pedagógica um campo tão absorvente) é que realmente grandes avanços na verdade foram feitos nos últimos anos, mas ainda existem razões para acreditar que estamos apenas no início de uma evolução mais emocionante ainda (RUNDELL, 1998, p. 338, tradução nossa) $)^{3}$.

Hartmann e Rundell, na década de 1990, quando pensam sobre o impacto do corpus na Lexicografia Pedagógica e refletem sobre o estado da arte dessa ciência, trazem à tona uma questão ainda atual na segunda década do século XXI: muito se

\footnotetext{
${ }^{2}$ I feel we are only at the start of an exciting period of real problem-solving.

${ }^{3}$ The paradox here (and this is what makes pedagogical lexicography such an absorbing field) is that really major advances have indeed been made in the intervening years, yet there are still grounds for believing that we are just at the start of more exciting developments still.
} 
evoluiu e tem-se evoluído, mas ainda há muito por fazer nesse campo de estudo, posto que o dinamismo da sala de aula impõe estar sempre em busca de soluções lexicográficas, entre as quais destacamos as relacionadas ao dicionário pedagógico, que respondam à demanda dos alunos em contexto de aprendizagem de língua.

Para Hartmann (2001), a Lexicografia Pedagógica desponta na intersecção entre o ensino de língua e o fazer de dicionários. É um campo da Lexicografia de orientação linguística, perspectiva interdisciplinar e natureza de resolução de problemas. O autor a concebe como uma área promissora, responsável por fomentar estudos e trabalhos de referência acerca dos learner`s dictionaries no contexto da língua inglesa britânica.

Molina García (2006) enfatiza ser a Lexicografia Pedagógica a Lexicografia sob a perspectiva do usuário e propõe serem três os aspectos gerais desta: a) ajuste da informação lexicográfica às necessidades do usuário; b) realização de inovações lexicográficas; c) desenvolvimento, por parte do lexicógrafo e do professor, das habilidades de referência do usuário. As habilidades de referência são aquelas necessárias para usar adequadamente um dicionário. O ajuste da informação refere-se à comunicação entre lexicógrafo e usuário/aprendente, porque, segundo o pesquisador, o uso do dicionário configura um ato comunicativo, o qual ocorre mediante a compreensão da informação lexicográfica (significados, questões gramaticais, combinações lexicais) pelo usuário. Por isso, a necessidade de estar ajustada às necessidades do consulente e primar pela compreensão.

Dubois e Dubois (1970, p. 54) já haviam atentado para a comunicação que se estabelece entre o autor do dicionário e o consulente. Trata-se, segundo os autores, de uma operação complexa, porque a informação encontrada pelo usuário no dicionário como resposta à sua dúvida passa por três estados: $1^{\circ}$ ) confrontação (o usuário confronta a informação lexicográfica com seu repertório cultural); $2^{\circ}$ ) compreensão (o consulente faz uma compreensão geral da resposta-enunciado lexicográfico); $3^{\circ}$ ) integração (a resposta dada pelo dicionário integra-se à bagagem cultural do usuário, 
modificando-a). Por esse motivo, Dubois e Dubois afirmam ser o dicionário uma obra do gênero didático, veiculador de um discurso pedagógico, posto o consulente não ser mais o mesmo após a consulta à obra lexicográfica: seu conhecimento linguísticocultural é, invariavelmente, ampliado.

Outro aspecto da Lexicografia Pedagógica mencionado por Molina García (2006) são as inovações lexicográficas, que pressupõem, segundo o pesquisador: facilidade para encontrar informação na macro e na microestrutura de unidades lexicais simples e complexas; avanços na apresentação de informações gramaticais, pragmáticas e semânticas - estas últimas com o uso de vocabulário controlado para as definições e de corpus para os exemplos -; estabelecimento de relações lexicais, semelhante à forma como criamos conexões para armazenar o léxico no cérebro, de modo a ser o dicionário um facilitador da aprendizagem dele. $\mathrm{O}$ autor assinala a necessidade de promover habilidades de referência, a fim de os alunos poderem aproveitar essas inovações, e de estimular o desenvolvimento da competência lexical. O desenvolvimento, por parte do lexicógrafo e do professor, das habilidades de referência do usuário deve ocorrer porque, para Molina García, o aluno desconhece todas as informações que uma obra lexicográfica pedagógica pode proporcionar e, por isso, não a usa em toda sua potencialidade ou dela faz uso inadequado. As razões para este comportamento do aluno em relação ao dicionário devem-se aos seguintes fatores: a) ideia de que o dicionário oferece apenas significados; b) não desenvolvimento das habilidades de referência; c) ausência do ensino das habilidades de referência nas ementas escolares e nos livros didáticos; d) influência do enfoque comunicativo no ensino, que relegou o dicionário a segundo plano, incentivando a inferência, por meio do contexto, dos sentidos das palavras desconhecidas. Em suma, as razões apontadas decorrem da ausência de letramento lexicográfico em contexto escolar.

Para Duran e Xatara (2007), a Lexicografia Pedagógica é uma especialização da Lexicografia, cujo foco não é a matéria lexicográfica, mas a proposição de subsídios 
para o aperfeiçoamento de dicionários que contemplem as habilidades dos usuários e atendam às suas necessidades linguísticas. Duran (2008) propõe ser a Lexicografia Pedagógica "fruto do conhecimento mais aprofundado sobre os aprendizes e suas dificuldades" (p. 83), portanto, "evolução lexicográfica", pois, a partir dela, começa-se a reconhecer e interpretar as necessidades dos usuários como soluções lexicográficas para superar as dificuldades linguísticas dos aprendizes de línguas. Interessante quando a autora esclarece, com base em Humblé (1997), o que seria, então, uma lexicografia não pedagógica: o não reconhecimento da finalidade pedagógica do dicionário, como ocorreu no século XVI, quando dicionários monolíngues, imbuídos do papel político de uniformizar as línguas, evitando que fossem corrompidas, tornam-se meros repositórios lexicais.

Hernández (2008) usa a expressão Lexicografia Didática ${ }^{4}$, recorrente na literatura especializada da Lexicografia espanhola, e afirma que, sem justificativa plausível, esta foi considerada, por muito tempo, uma disciplina menor da Lexicografia. Uma das razões para tal é a pouca importância atribuída, social e academicamente, à educação, e, especialmente na Espanha, a situação de escasso interesse e consideração aos assuntos do âmbito da Didática de Línguas. Essa situação favoreceu, assim, a adoção de expressões da língua inglesa, por exemplo, learner dictionary, traduzido, na língua espanhola, para diccionario de aprendizaje e empregado como sinônimo de dicionário escolar. Para Hernández (2008), a Lexicografia Pedagógica é a parcela da Lexicografia voltada a dicionários para estudantes de línguas, cujos pressupostos teóricos e aplicações práticas visam atender a dois

\footnotetext{
${ }^{4}$ Em Krieger (2006), há, igualmente, referência a essa ciência como Lexicografia Didática. O uso dos adjetivos didático e pedagógico tem sido motivo de reflexão entre os pesquisadores da área. Para Welker (2008), o adjetivo pedagógico refere-se ao dicionário elaborado para atender às necessidades de estudantes de línguas. Já o adjetivo didático deve ser empregado para fazer referência à maneira como as informações lexicográficas são apresentadas, de maneira clara e adequada (didática) ou de forma inadequada (pouco didática).
} 
públicos-alvo: 1) crianças e jovens aprendentes da LM, 2) jovens e adultos, estudantes de LE.

Para Krieger (2011), embora a Lexicografia Pedagógica seja recente em nosso país, esta vem se expandindo, devido à importância, tardia, certamente, atribuída às obras lexicográficas nos espaços de educação. Por isso, os contornos de seu objeto de estudo ainda estão sendo delineados. No entanto, pode-se delimitar como sendo seu princípio orientador a relação entre dicionário e ensino de línguas: o espaço por ele ocupado nas aulas de línguas, materna ou estrangeira, e a preocupação com sua adequação e qualidade, de modo a desvelar seu potencial didático, tornando seu uso produtivo e voltado para o ensino.

Welker (2008a, 2011), ao traçar o panorama da Lexicografia Pedagógica, sinaliza a ausência deste termo em obras importantes da Lexicografia - Enciclopédia Internacional de Lexicografia, de Hausmann et al. (1989/1990/1991), enciclopédia de Martínez de Sousa (1995) e enciclopédia editada por Brown (2006) - e nas introduções ao assunto, como em Landau (1984/2001), Béjoint (1994/2000), Lara (1997) e Jackson (2002). E, quando usado, esse termo, geralmente, restringe-se aos learner's dictionaries. O pesquisador reconhece faltar uma definição precisa do que é a Lexicografia Pedagógica e seu objeto de estudo e propõe que a "LP [Lexicografia Pedagógica] inclui dicionários destinados a aprendizes tanto de línguas estrangeiras quanto da língua materna" (WELKER, 2008b, p. 18), ressaltando serem de interesse à Lexicografia Pedagógica prática as habilidades, dificuldades e necessidades de consulta dos alunos de línguas para a elaboração de dicionários pedagógicos, os quais devem diferir de acordo com os níveis de competência linguística dos usuários. Por sua vez, o foco da Lexicografia Pedagógica teórica (Metalexicografia Pedagógica) é o estudo dos dicionários pedagógicos. Pesquisas de uso de dicionário não pedagógico (de língua geral, por exemplo, o Dicionário Aurélio da Língua Portuguesa) não se enquadram na perspectiva da Lexicografia Pedagógica, fazendo parte do campo da Pesquisa sobre o 
uso de dicionários, bem como não se enquadram no ensino do uso do dicionário, que compete à Pedagogia/Didática de dicionários.

De Schryver (2012), ao revisitar o fazer lexicográfico em língua inglesa dos últimos 25 anos do prestigiado periódico International Journal of Lexicography (IJL), criado em 1988 pela EURALEX, e dos últimos 50 anos dos mais importantes periódicos, manuais, enciclopédias, conferências e livros sobre Lexicografia, apresenta um horizonte dos temas lexicográficos mais discutidos e pesquisados desde 1962. Verificando a ocorrência do termo pedagogical nos textos da área, o autor aponta o crescente interesse pelo dicionário pedagógico, logo, pela Lexicografia Pedagógica, ao longo do tempo, interesse este que vem aumentando e consolidando-se ano após ano. De acordo com dados gráficos apresentados, começou a haver interesse pelo assunto, no âmbito do IJL, no final da década de 1990, atingindo ápice nos anos de 2007 e 2012. Para além do contexto deste periódico, desde 1962, verifica-se interesse pelo assunto, com interrupção na década de 1970 . No fim da década de 1980, retoma-se a pesquisa na área, e o final da década de 1990 e começo da década de 2010 são momentos de intensa produção acadêmica.

\section{A Lexicografia Pedagógica em contexto brasileiro}

Duran e Xatara (2007) propõem haver quatro atores no cenário da Lexicografia Pedagógica: o(a) lexicógrafo(a), o editor, o professor e o aluno. $\mathrm{O}(\mathrm{a})$ lexicógrafo(a) produz o dicionário e, com frequência, em sua prática, faz pesquisa sobre dicionário, ainda que, na literatura especializada, seja feita a divisão entre lexicógrafo(a) (autor de dicionários) e metalexicógrafo(a) (pesquisador de dicionários). O editor publica e comercializa a obra lexicográfica, visando, muitas vezes, ao baixo custo e à alta qualidade, de modo a obter vendas exitosas e lucros notáveis. O professor influencia sobremaneira os alunos no momento de uso do dicionário e na escolha deste, como comprovado em Vargas (2011). E o aluno é o ator protagonista, público-alvo dos dicionários de viés pedagógico, principal foco das pesquisas na área, já que conhecer 
sua identidade e suas necessidades confere maior clareza ao(à) lexicógrafo(a) (e metalexicógrafo/a) em suas decisões sobre o que e como produzir.

A proposta de Duran e Xatara (2007), parece-nos que pode ser complementada com mais um elemento no cenário brasileiro da Lexicografia Pedagógica: o Governo Federal, o qual realiza suas ações, nesse contexto, por meio das ações do Ministério da Educação (MEC). O MEC, por algumas décadas, distribuiu, à rede pública de ensino, dicionários de latim, língua portuguesa e línguas estrangeiras. Por quase 20 anos, as obras lexicográficas deixaram de ser oferecidas às escolas, voltando a ser distribuídas na primeira década do século XXI, quando o Programa Nacional do Livro Didático (PNLD) incorporou, em sua avaliação, dicionários para o ensino da LM. O PNLD avalia e distribui coleções de livros didáticos às escolas públicas brasileiras dos três segmentos da Educação Básica: anos iniciais do Ensino Fundamental, anos finais do Ensino Fundamental e Ensino Médio. Igualmente, contempla alunos da educação especial.

Em 2006, o Programa inovou, propondo uma tipologia de dicionários e a criação de acervos lexicográficos para a sala de aula, e, em 2012, foi criado o PNLDDicionários, vertente do Programa específica para as obras lexicográficas, que aprimorou o que já vinha sendo feito e, mais uma vez, inovou, acompanhando os dicionários do livro Com direito à palavra: dicionários em sala de aula, publicação do MEC, elaborado por Egon Rangel, com colaboração de Marcos Bagno e Orlene de Sabóia Carvalho, cujo público-alvo são os professores e a finalidade é apresentar informações sobre os dicionários e as características dos acervos, e propostas de atividades com as obras lexicográficas para serem aplicadas em sala de aula.

Essas ações do Governo Federal, conforme Krieger (2006b) e Rangel (2011), na última década, tiveram grandes impactos nas esferas acadêmica, editorial e escolar, posto que fomentaram pesquisas no âmbito da Lexicografia Pedagógica, estimularam a preocupação dos editores em produzir dicionários escolares de qualidade 
pedagógica, evidenciaram o potencial didático da obra lexicográfica no ensino de variadas disciplinas, não apenas da LM, e levaram, certamente, professores, alunos e pais a refletirem sobre o papel do dicionário, na sala de aula e em casa, e as contribuições dele para o ensino. Portanto, o Governo Federal assume relevância no cenário da Lexicografia Pedagógica brasileira, com ações que impactam em todos os âmbitos: desde editorial, no momento de produção do dicionário, até escolar, no momento de fazer uso dele.

Duran e Xatara (2007) também propõem ser a Lexicografia Pedagógica multifacetada, sendo três as áreas com as quais faz interface: a Linguística Computacional, visto que o computador é, na atualidade, ferramenta imprescindível para elaborar dicionários, fornecedor de dados de conteúdo, possibilidade de inclusão de novas mídias, de concepção de novos formatos de obras lexicográficas e de interação com os usuários; a Linguística de Corpus, porque os corpora indicam a frequência da unidade lexical, informações semânticas, comportamento combinatório, exemplos, dados da linguagem espontânea e registro, proporcionando, dessa forma, grande número de informações ao lexicógrafo, cabendo-lhe avaliá-las e selecioná-las para compor a obra lexicográfica; e a Linguística Aplicada, pois compartilha de mesmo interesse - verificar meios de potencializar a aprendizagem de línguas, sobretudo, a aquisição do léxico - e contribui com suas metodologias de pesquisa.

No contexto do letramento lexicográfico, Krieger (2011) menciona outra área com a qual a Lexicografia Pedagógica tem interface: a formação de professores. A ausência de formação lexicográfica, na graduação e/ou pós-graduação, compromete o uso do dicionário como material complementar para o ensino de línguas e contribui à perpetuação da ideia de que é um livro somente de consultas esporádicas. De Grandi (2014), atenta a essa questão, elaborou e apresentou, em sua dissertação de Mestrado, um Guia teórico-metodológico, com propostas de atividades para o professor de Espanhol como Língua Estrangeira (E/LE) aprender a usar o dicionário, especialmente 
o bilíngue, e ensinar os alunos a usarem-no. O Guia, de acordo com a pesquisadora, pode contribuir para o conhecimento de conceitos da Lexicografia Pedagógica e o uso mais produtivo da obra lexicográfica, na qualidade de apoio para a preparação de aulas e no ensino da língua.

Desse modo, do panorama interdisciplinar da Lexicografia Pedagógica, em contexto brasileiro, fazem parte: aluno (ator protagonista), lexicógrafo, editor(a), professor(a) e Governo Federal. Na resolução dos problemas encontrados na sala de aula, a fim de produzir dicionários pedagógicos mais produtivos e orientados para o ensino, esta especialização pedagógica da Lexicografia trava constante diálogo com a Linguística Aplicada, a Linguística Computacional, a Linguística de Corpus e a Formação de professores, na graduação e/ou pós-graduação.

Figura 1 - Panorama da Lexicografia Pedagógica em contexto brasileiro.
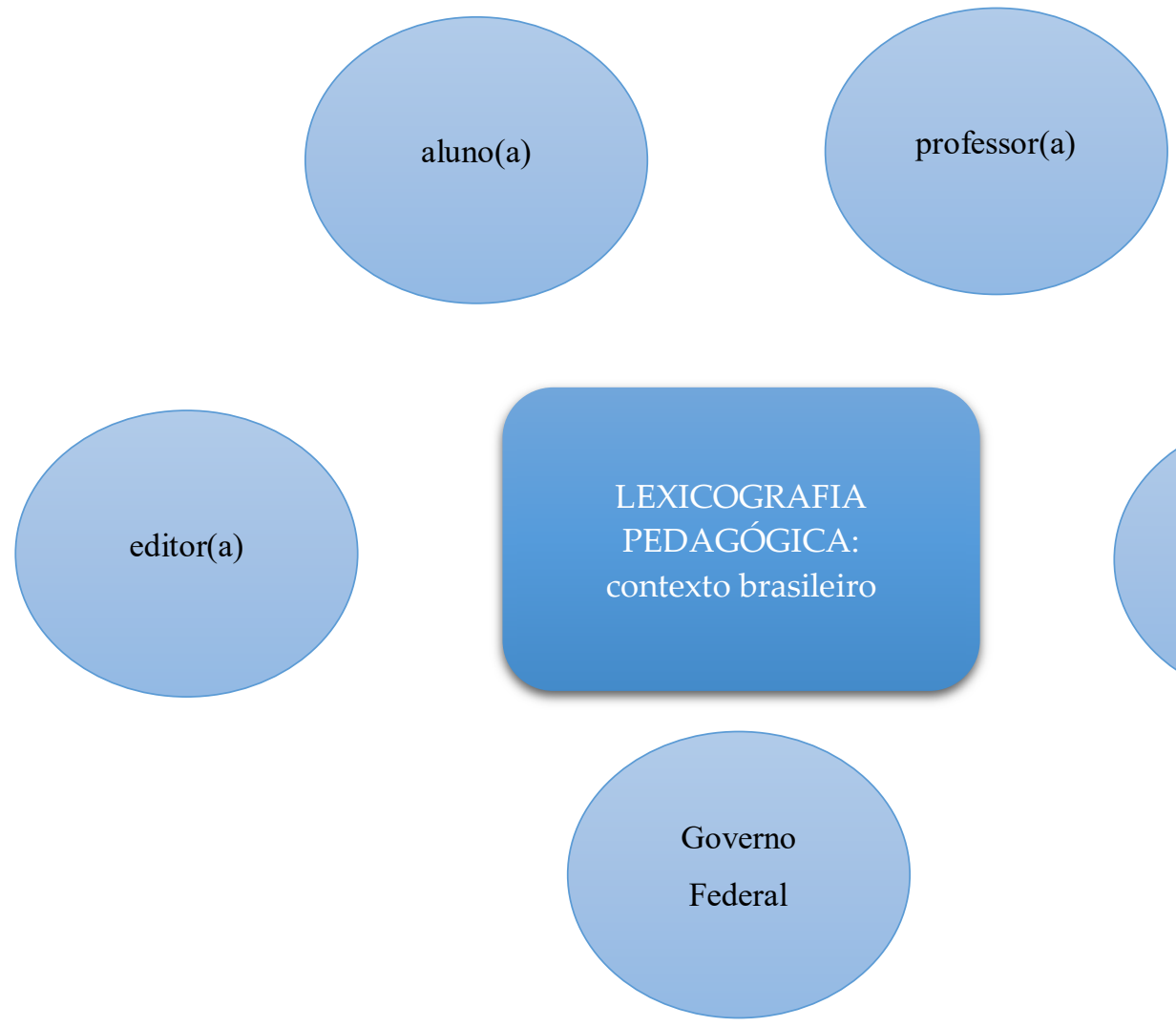

Fonte: elaborado pela autora. 


\section{Considerações finais}

Ao longo deste artigo, fizemos um resgate das origens da Lexicografia Pedagógica, as quais remontam ao final do século XIX e início do século XX, quando há uma mudança de paradigma no ensino de línguas e o Método Direto ganha força nas salas de aula. A partir de então, começa-se a pensar na necessidade da elaboração de materiais didáticos e repertórios lexicais que atendam às necessidades linguísticocomunicativas dos estudantes, e os primeiros estudos em Lexicografia Pedagógica são empreendidos.

Igualmente, apresentamos o estado da arte dessa ciência nas últimas duas décadas, de 1992 a 2012, resgatando vozes de pesquisadores brasileiros e estrangeiros. Os conceitos sobre Lexicografia Pedagógica por estes elaborados permitem-nos definila como uma disciplina cujos focos são a proposição de parâmetros para a elaboração de dicionários pedagógicos e a produção destes, e o público-alvo é o estudante de LM e/ou LE. Sua verve é o que acontece nos espaços educacionais de ensino, tais como, as necessidades linguísticas dos estudantes e as habilidades no manuseio do dicionário, o qual, nessa perspectiva, é concebido como material didático, de fim primeiro e último, obviamente, pedagógico. Dessa forma, este deve auxiliar no ensino de línguas e, por que não, de outras disciplinas, como se pressupõe no PNLD-Dicionários, comunicando, estabelecendo diálogo e interagindo com seu usuário, o estudante. A Lexicografia Pedagógica é, portanto, a área do âmbito lexicográfico cujas teoria e prática estão em constante diálogo, pois a solução de problemas reais na relação ensino-dicionário pedagógico é sua finalidade primeira.

Por fim, ampliando a proposta de Duran e Xatara (2007), apresentamos o panorama da Lexicografia Pedagógica em contexto brasileiro, do qual fazem parte lexicógrafo(a), aluno(a), professor(a), editor(a) e Governo Federal. Igualmente, tecemos reflexões sobre o caráter interdisciplinar e multifacetado da Lexicografia Pedagógica. Esta comunica-se com outras áreas, dentro e fora da Lexicografia, da 
Linguística e da Educação, com vistas a manter ou tornar harmoniosa a relação ensinoaprendizagem de línguas e uso do dicionário pedagógico.

Esperamos, com este texto, ter contribuído para o desenvolvimento dos estudos em Lexicografia Pedagógica, bem como para a valorização dessa disciplina nos cursos de graduação e pós-graduação em Letras e Linguística.

\section{Referências bibliográficas}

DE GRANDI, L. Uso do dicionário no ensino de língua espanhola: proposta de Guia teórico-metodológico para professores. 2014. Dissertação (Mestrado em Linguística e Língua Portuguesa) - Faculdade de Ciências e Letras, Universidade Estadual Paulista "Júlio de Mesquita Filho", Araraquara, 2014.

DE SCHRYVER, G.-M. Trends in twenty-five years of Academic Lexicography. International Journal of Lexicography, v. 25, n. 4, p. 464-506, 2012. DOI: https://doi.org/10.1093/ij1/ecs030

DUBOIS, J.; DUBOIS, C. Introduction à la lexicographie: le dictionnaire. Paris: Larousse, 1971.

DURAN, M. S. Parâmetros para a elaboração de dicionários bilíngues de apoio à codificação escrita em línguas estrangeiras. 2008. Tese (Doutorado) - Instituto de Biociências, Letras e Ciências Exatas, Universidade Estadual Paulista "Júlio de Mesquita Filho", São José do Rio Preto, 2008.

DURAN, M. S.; XATARA, C. M. Lexicografia Pedagógica: atores e interfaces. Delta: Documentação de Estudos em Linguística Teórica e Aplicada, São Paulo, 2007.

GOUWS, R. H. Theoretical Lexicography and the International Journal of Lexicography. International Journal of Lexicography, v. 25, n. 4, p. 450-463, 2012. DOI: https://doi.org/10.1093/ijl/ecs028

HARTMANN, R. R. K. Teaching and researching Lexicography. England: Pearson Education Limited, 2001.

HARTMANN, R. R. K. Theory and practice in dictionary-making. In: Lexicography: principles and practice. HARTMANN, R. R. K. (org.). London: Academic Press, 1983. p. 3-12. 
HERNÁNDEZ, H. Retos de la Lexicografía Didáctica. In: EL DICCIONARIO COMO PUENTE ENTRE LAS LENGUAS Y CULTURAS DEL MUNDO, 2008, Alicante. Actas del II Congreso Internacional de Lexicografía Hispánica. Alicante: Biblioteca Virtual Miguel de Cervantes, 2008. p. 22-32. Disponível em: http://descargas.cervantesvirtual.com/servlet/SirveObras/03692741069236462977857/0 31297.pdf?incr=1. Acesso em: 26 fev. 2018.

HUMBLÉ, P. A new model for a foreign language learners' dictionary. 1997. Tese (Doutorado em Letras). Universidade Federal de Santa Catarina, Florianópolis, 1997.

KRIEGER, M. da G. Políticas públicas e dicionários para escola: o Programa Nacional do Livro Didático e seu impacto sobre a lexicografia didática. Cadernos de Tradução, Florianópolis, v. 18, p. 235-252, 2006.

KRIEGER, M. da G. Questões de lexicografia pedagógica. In: XATARA, C.; BEVILACQUA, C. R.; HUMBLÉ, P. R. M. (org.). Dicionários na teoria e na prática: como e para quem são feitos. São Paulo: Parábola Editorial, 2011. p. 103-113.

MOLINA GARCÍA, D. Fraseología bilingüe: un enfoque lexicográfico-pedagógico. Granada: Comares, 2006.

RANGEL, E. de O. Dicionários escolares e políticas públicas em educação: a relevância da "proposta lexicográfica". In: CARVALHO, O. L. de S.; BAGNO, M. (org.). Dicionários escolares: políticas, formas \& usos. São Paulo: Parábola Editorial, 2011. p. 37-60.

RUNDELL, M. Recent Trends in English Pedagogical Lexicography. International Journal of Lexicography, v. 11, n. 4, p. 315-342, 1998. DOI: https://doi.org/10.1093/ijl/11.4.315

WELKER, H. A. Panorama geral da lexicografia pedagógica. Brasília: Thesaurus, 2008a.

WELKER, H. A. Lexicografia pedagógica: definições, história, peculiaridades. In: XATARA, C.; BEVILACQUA, C. R.; HUMBLÉ, P. R. M. (org.). Lexicografia Pedagógica: pesquisas e perspectivas. Florianópolis: UFSC, 2008b. p. 9-45.

WELKER, H. A. Questões de lexicografia pedagógica. In: XATARA, C.; BEVILACQUA, C. R.; HUMBLÉ, P. R. M. (org.). Dicionários na teoria e na prática: como e para quem são feitos. São Paulo: Parábola Editorial, 2011. p. 103-113. 